\title{
A CONCEPTUAL FRAMEWORK FOR LINE MANAGERS' HRM IMPLEMENTATION EFFECTIVENESS: INTEGRATING SOCIAL CONTEXT AND AMO THEORIES
}

\section{DOI: 10.17261/Pressacademia.2015211620}

Gaye OZCELIK ${ }^{1}$, Cavide UYARGIL ${ }^{2}$

${ }^{1}$ Okan University. E-mail: gaye.ozcelik@okan.edu.tr

${ }^{2}$ İstanbul University. E-mail: cuyargil@istanbul.edu.tr

\section{Keywords:}

Social Context Theory, AMO Theory, HRM, Line Managers' HRM Implementation Effectiveness, HR Specialists

\section{Jel Classification:}

\section{M0, M1}

\section{ABSTRACT}

Over recent decades, there has been an important stream of research that has examined the human resources management (HRM) and organizational effectiveness relationship. However, few of these studies have paid attention to developing perspectives regarding effective HRM implementation. Such implementation is a process that is not only executed by HR managers, for it is also the responsibility of line managers and other employees of the organization. Increasingly, the responsibilities of HRM are being passed on to line managers, who have thus become more involved in dealing with their employees' HRM issues. This study is aimed at investigating the factors that can influence the degree to which effective HR practices are implemented, going further than previous theoretical studies by proposing a conceptual model of HR implementation effectiveness. We incorporate the social context theory and AMO theory into the model. Social context factors of organizational culture, organizational climate, and political considerations as features of the work environment and top management's HR support as a higher-order social context dimension are proposed as drivers for effective implementation of HR systems and practices. The model also considers abilitymotivation-opportunity factors as one set of variables that mediates the relationship between social context variables and line managers' HR implementation effectiveness. This study tries to step into an area of study which has not been comprehensively explored by the scholars. It involves putting forward a model of $\mathrm{HR}$ implementation effectiveness by considering the role of line managers and a set of propositions for testing in field. The propositions developed in the model provide guidelines for further study in the focal HRM topic that we believe will generate beneficial findings for both practitioners and academics. 


\section{INTRODUCTION}

In recent decades, there has been an important stream of research that has examined the human resources management (HRM) and organizational effectiveness relationship. A few of the most recent studies have been focused on effective HRM implementation (Sikora \& Ferris, 2014; Bos-Nehles, Van Riemsdijk \& Looise, 2013; Guest, 2011). However, most scholarship has paid attention to the design and quality of HRM practices rather than their implementation in real world contexts (Khilji \& Wang, 2006; Wright and Nishi, 2006; Huselid, et al., 1997). It is not merely the quality of a proposed HR system that drives the HRM-organizational effectiveness relationship, for successful implementation is also paramount (Chow, 2012). Vermeeren (2014) goes further when he states that the actual HR system being implemented by organizational members determines effectiveness, rather than the intended HR system as designed by an HR department. That is, HRM implementation is not simply executed by HR managers but also by line managers and employees of the organization. Consequently, there have been increasing calls for line managers to act as business partners in conjunction with HR and other employees regarding HR processes (Renwick, 003). In effect, HRM implementation by line managers in relation to their subordinates' employment issues has become increasingly commonplace in recent years (Bos-Nehles, Van Riemsdijk, Looise, 2013; Maxwell \& Watson, 2006). Renwick (2003) notes that significant numbers of line managers want to get involved in sharing HR responsibilities with HR specialists, and that they take these responsibilities very seriously.

However, some academics have highlighted the complex and sometimes conflicting relationship between HR specialists and line managers. Sikora and Ferris (2014) argue that line managers may resist, fail to cooperate or simply ignore their HR responsibilities for various reasons, such as lack of trust between the parties and/or high work load levels. This can lead to lower employee involvement and undesirable employee attitudes and behaviors. In fact, it could be argued that the weaker the line manager involvement, the lower the organizational performance levels will be. Accordingly, Wright, McMahan, Snell and Gerhart (2001) contend that no matter how effective the HR practices are in theory, if line managers are not proactively involved in implementing them, top performance levels cannot be attained by the firm. That is, implementation of effective HR practices is fundamental to employee management success and improved firm performance (Becker \& Huselid, 2006; Gratton \& Truss, 2003).

The issues noted above prompt our investigation into the factors that can influence the degree to which effective HR practices are implemented. This work goes beyond previous theoretical studies in that it involves putting forward a model of HR implementation effectiveness and a set of propositions for testing in field. We incorporate social context theory (Ferris, Arthur, Berkson, Kaplan, Harrell-Cook and Frink, 1998) and AMO (AbilityMotivation-Opportunity) theory (Appelbaum, et al., 2000) in the model, which is also supported by two different frameworks provided by Sikora and Ferris (2014) and BosNehles et al. (2013). Specifically, Sikora \& Ferris (2014) sought to explain line managers' HRM implementation in terms of social contextual factors whereas Bos-Nehles, et al. (2013) applied AMO theory for analyzing line managers' HRM effectiveness. 


\section{THEORETICAL PERSPECTIVES}

\subsection{AMO Theory}

The abbreviation AMO stands for ability-motivation-opportunity (Appelbaum, et al., 2000). According to AMO, in order for a firm to achieve improved organizational performance, it is necessary that employees demonstrate discretionary effort in performing their jobs as a result of applied HRM practices. The discretionary effort relates highly to the conditions that;

a. Employees have the required abilities and skills for doing their jobs effectively,

b. Employees are motivated to put extra effort into performing their tasks,

c. Employees are provided with the opportunity to use their skills and are encouraged to express themselves.

From the above it can be seen that the AMO model adopts an employee-based perspective for linking people's ability-motivation-opportunity when implementing HRM practices with firm performance (Appelbaum, et al., 2000). By contrast, Bos-Nehles et al. (2013) take a managerial-perspective that focuses on line managers' ability-motivationopportunity for effective HRM practices, claiming that even well-designed HRM systems do not by themselves guarantee a high degree of effectiveness in HRM implementation, for line managers' performance level is heavily influential on this effectiveness. Further, Alfes, Truss, Soane, Rees, Gatenby (2013) mention that significant differences exist among the intended, implemented and perceived HRM practices. Therefore, it is important to consider the line managers' role in HRM effectiveness. From an HRM perspective, ability refers to line managers' capacity to execute better HR practices such as using appropriate selection, hiring techniques, training instruments, competently assessing subordinates' performance, etc. Motivation pertains to their being willing to accept the HR roles and be rewarded for their effective behaviors, whilst opportunity is about getting the necessary resources and support for accomplishing their HR roles. In keeping with this, Sterling and Boxall (2013) have recently argued that enabled work contexts are important for developing employee abilities and motivation as these environments provide the individuals with opportunities such as information and technology as well as supportive line managers and co-workers.

Under the AMO framework, employee performance is taken as being a function of ability $(A)$, motivation (M) and the opportunity to perform (O). According to the classical workperformance theories put forward by scholars such as Vroom (1964) and Blumberg and Pringle (1982), there should be an interactive effect of these factors for attaining performance. This suggests that ability, motivation or opportunity cannot deliver performance all by themselves and that each should be present to some degree, for if one is absent then performance becomes zero. Recent work by Siemsen, Roth \& Balasubramanian (2008) and Boxall and Purcell (2011) supports the complementary effect of the AMO model as depicted by the formula: $P=f(A \times M \times O)$. 


\subsection{Social Context Perspective}

Social context is an important mechanism, involving culture, climate, political considerations and social interaction factors and/or processes that generate an environmental and organizational framework for understanding the link between HRM systems, HR practices and organizational success (Ferris, et al., 1998). These factors/processes act as antecedents for the formulation and development of effective $H R$ systems and practices (Sikora \& Ferris, 2014; Bowen \& Ostroff, 2004; Ferris et al., 1998). Bowen and Ostroff (2004) have considered the issue from a higher-level social contextual perspective in that they have stressed the importance of top management's HR support for the success of HR. In order to comprehend the social context perspective, it is necessary to make some explanations with regard to these contextual dimensions and their linkages with HRM systems.

Organizational culture refers to the organizationally embedded shared attitudes, beliefs, and core values of a firm's members. Formal management systems including HRM systems and practices as well as informal communication mechanisms provide important indicative cues about the organization's culture. For instance, organizations that are not flexible to change usually have HR systems that are either ignored by the workforce or used ineffectively (Sikora \& Ferris, 2014). Organizational climate pertains to employees' common interpretation of the work environment including events, practices, policies, procedures, as well as the sort of attitudes and behaviors that are deemed appropriate (Bowen \& Ostroff, 2004). Climates that foster the achievement of performance goals, such as high customer satisfaction, improved service quality, etc., are likely to result in rewards and bonuses for realizing these goals, which in turn will increase line managers' efforts to ensure successful HR implementation. Sikora \& Ferris (2014) have found evidence that line managers' achievement of HR tasks correlates with the attractiveness of incentives on offer.

The political perspective in organizations is grounded in the fact that various individuals and groups with diverse interests existing in organizations is a reality of life that has to be lived with (Ferris \& Judge, 1991). Organizational politics have been defined as "a social influence process with potentially functional or dysfunctional consequences"(Ferris \& Judge, 1991; 449) or as Pfeffer (1981b; 7) puts it; "the study of power in action". Political activities in organization can range from conflicting interest resolution to forging coalitions with diverse interests and using power to influence decision making. Political behaviors are likely to have an impact on HR related actions. For instance, accountability is an important situational characteristic of political behavior and line managers, who are held accountable as the decision makers for selecting employees, may prefer to select individuals who are similar to themselves and tactically work to bring them into the company or have them promoted. In so doing, it is easier for them to build coalitions in order to strengthen their power base in the organization.

As to top management support, as mentioned above, Ferris et al. (1998) focus on the social context perspective as having an influence on HR systems and practices. Bowen and Ostroff (2004) also point to a 'higher-level' social context factor, namely, top management HR support. 
Accordingly, as long as top management significantly regards the HR function as providing 'value' to the organization rather than see it merely as a 'cost' and thus, not hesitating to make important investments in HRM, clearly, under such circumstances HR is perceived as a high-credible function with significant authority. Consequently, an important message will be sent to all organizational members that HR has its own 'legitimacy', which will lead to an increase in line managers' efforts towards HR implementation. Cordial social interactions between line managers and the HR Department are likely to have a positive influence on the degree of effectiveness in HRM implementation (Sikora and Ferris, 2014). Moreover, the supportive role of top management regarding HRM practices cannot be disregarded in the social interactions because the success of the HR function in the organization is closely associated with their supportive input. For this reason, the top management HR support dimension is also added to the model of this study.

\section{CONCEPTUAL FRAMEWORK AND PROPOSITIONS}

\subsection{The Model of the Study}

In this model, the social context factors of organizational culture, organizational climate and political considerations as features of the work environment are proposed as being the drivers of effective implementation of HR systems and practices. In addition to these dimensions, the model deployed incorporates a higher-order social context factor, namely HR support coming from top management. Bowen \& Ostroff (2004) briefly stated that top management should be considered as a factor in their article, but they did not incorporate it into their original model. Taking the AMO perspective into account, our model considers ability-motivation-opportunity factors as one set of mediating variables for probing the relationship between social context variables and line managers' HR implementation effectiveness. Further to this, Boxall and Purcell (2011) assert that employee ability, motivation and opportunity are an essential set of mediators for inclusion in any model of HRM. The model is designed so as to take into account the fact that how well the HRM practices are designed and how effective they are actually implemented can vary. Moreover, no matter how well-set up the HR practices are, they have no far reaching influence on performance when line managers are not able to or do not wish to implement them (Sikora \& Ferris, 2014). Hence, it is essential that what is intended to be implemented should actually match with what is put into practice. On the other hand, as HR tasks are increasingly being devolved to line managers individual differences need to be taken into consideration. These stem from their varying abilities and motivation and also the opportunities they expect to take advantage of in the work environment. In addition, the effect of the social context factors on the abilitymotivation-opportunity of line managers is also proposed as a topic requiring investigation. As depicted in the model, it is proposed that organizational culture and climate as well as political considerations can either foster or hinder opportunities provided for line managers in the work environment for HR related decision-making and hence, influence their knowledge, skills and motivation level in relation to effective HR implementation. 
In general, our model is designed on the assumption that ability-motivation-opportunity and social context factors including higher-order social context dynamics, i.e. top management HR support, play significant roles in line managers' HR implementation effectiveness. The key mediating role of AMO factors between the social-context factors and $\mathrm{HR}$ implementation effectiveness relationship is central to the model's construction.

Figure 1: A Theoretical Model for Line Managers' HR Implementation Effectiveness

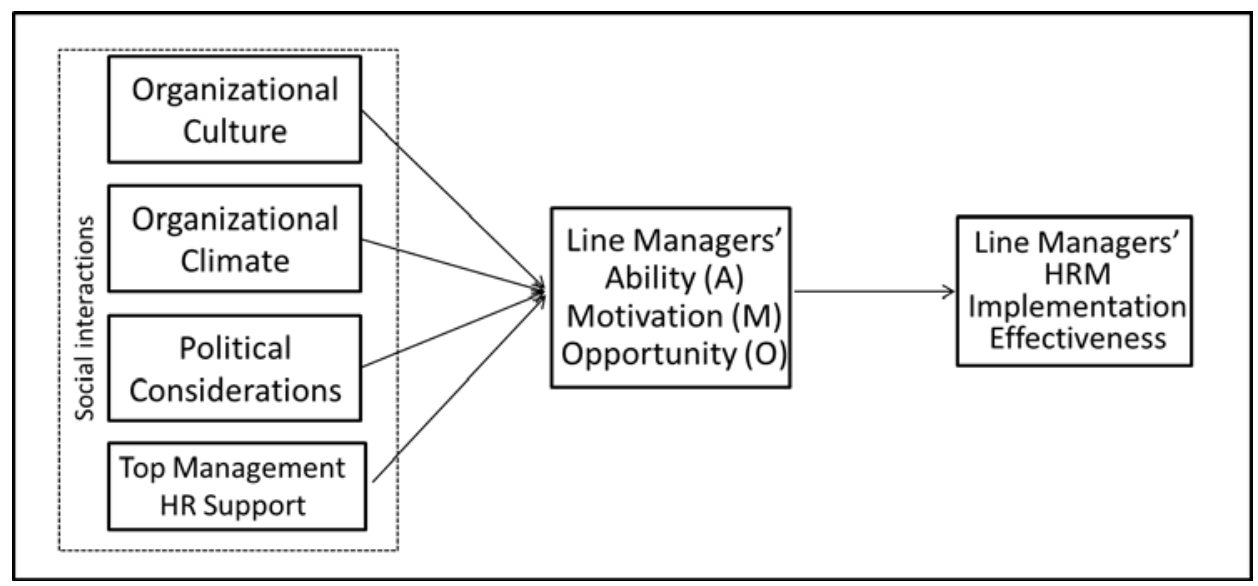

\subsection{The Propositions}

Organizational culture is made up of a network of values, norms, beliefs, assumptions and experience, which individuals in the organization learn, internalize and share over time (Rousseau, 1990; Schein, 1984). Schein (1984) argues that this culture is a process through which an organization's principles are transfused into its people and also taught to new members. In fact, top management and all employees in the organization learn and adopt the common norms of culture over time. Similarly, Sikora and Ferris (2011) assert that organizational norms and attitudes shape line managers' behavior in relation to implementing business practices. This means that having a well-structured HRM system is important but not necessarily sufficient for its effective implementation.

Adowele and Anthonia (2013) assert that organizational culture is composed of a set of factors according to which human behavior in the organization is established and this varies across organizations. Organizational norms that attach importance to HR practices are more likely to provide the managers with the necessary opportunities to use their skills and also are more likely to motivate them (Sikora \& Ferris, 2014). The more organizations focus on training managers and employees in recruitment practices, such as behavioral interviewing or interpretation of data collected about individuals in the selection process, the more skilled they will be at selecting their employees (Omotayo et al., 2013). Regarding the influence of organizational culture on HRM, Nyameh (2013) also finds that there is a positive relationship between the culture, HRM practices and employee's performance and hence, arrives the idea that organizations should place emphasis on managing their cultural dynamics as this can give positive results on performance. 
Conversely, when the organizational norms undermine the use of effective HR implementation, then line managers are reluctant to translate people management practices into reality (Sikora and Ferris, 2014).

\section{Proposition 1. An organizational culture supportive of effective HR practices is positively associated with improvements in line managers' AMO.}

Organizational climate has been defined by many scholars as a shared perception of employees about issues regarding the goals pursued by the organization, the way daily work activities are implemented and the sort of behaviors expected, rewarded or punished (Bowen \& Ostroff, 2004). The climate sets the path as to how individuals in the organization are communicated with about HR policies and practices, which helps engender a shared perception about how HR is to be executed (Li, Frankel \& Sanders, 2011). What fosters a strong organizational climate are the three features of: distinctiveness, consistency and consensus. That is, such climates contribute not only to strong HRM practices which are also distinctive, consistent among each other and which are collectively agreeable, but also to a convergent comprehension by all members of the organization with regard to these practices. Additionally, Bowen and Ostroff (2004) claim that positive climates help increase the motivation of members of the organization in performing desired skills, attitudes and behaviors. It may also be expected that strong and positive organizational climates provide line managers with the opportunity to participate in $\mathrm{HR}$ related decision-making and with the motivation to perform HR tasks appropriately. From this, the following proposition can be inferred:

\section{Proposition 2. A strong and performance-rewarding organizational climate is positively associated with improvements in line managers' AMO.}

HRM is composed of systems and practices in relation to which political considerations need to be taken into account. This is based on the assumption that political behaviors in organizations, such as coalition formation, lobbying and withholding information affect HRM decisions and actions regarding selection, performance appraisal, etc. (Sikora \& Ferris, 2014). An organization might have established very structured and strong human resource management practices which are aimed at fair and objective selection, development and retention of promising individuals. Nevertheless, what is intended can be different from what the actuality is owing to political considerations, for political influence can be exercised in employee management practices both on the applicant/employee side as well as that of the manager. For instance, in the employee selection process managers may be intentionally or unintentionally more motivated to prefer individuals similar to themselves and project positive impressions in order to influence job applicants' job choices (Ferris \& Judge, 1991). In which case, line managers might not put effort into using their ability to find the right person for the right job which may result in their unjust attitudes. Greenberg (1988) previously argued that it is not line managers' concern to ensure fairness or justice but to portray an image of fairness. Accountability is one of the dimensions of political behavior, which as Renwick (2000) points out is complementary to responsibility in relation to the execution of line managers' duties. Consequently, as long as line managers are tasked with being held accountable for HR implementation practices, then their motivation and effort for executing them will increase (Sikora \& Ferris, 2014). 
However, the degree of accountability given to those managers shall not lead them to present favorable impressions in order to seem acceptable to influential others in the organization (Ferris \& Judge, 1991).

\section{Proposition 3. Political considerations focusing on HR accountability are positively associated with improvements in line managers' AMO.}

It is predominantly top management that sets the parameters of the organization at the establishment level. Reagrding which, the senior management of an organization can cultivate the idea that HR is a "business partner" or merely a "passive administrator" (Whittaker and Marchington, 2003). Those managers that view HR as a business partner treat this function equally with the other functions of the organization, thus providing the required resources and support for effective HR practices. In respect of this, a key issue is whether HR responsibilities are explicitly taken as part of the performance criteria in the same way as production and service goals (Whittaker and Marchington, 2003). A company's top management should set policies for full support of HRM practices design and implementation (Camelo Ordaz, De La Luz Ferna'ndez-Alles, Valle-Cabrera, 2008), for by so doing, line managers' AMO will be improved.

\section{Proposition 4. Greater top management support for effective HR practices is positively associated with improvements in line managers' AMO.}

It has been argued that line managers and those responsible for HR have to be in close partnership in order to deliver effective HR outcomes (Sikora \& Ferris, 2014). Regarding which, Torrington and Hall (1996) previously asserted that an HR/line management partnership enables effective HR strategy execution. Social interactions that contribute to their level of partnership in terms of putting HR into effect have been found to be important (Sikora \& Ferris, 2014). Moreover, line managers' view of the HR department is a criterion that can improve or impede the level of interaction. For instance, Whittaker \& Marchington (2003) argue that some line managers criticize the degree of the HR department's contribution to organizational outcomes, claiming they are not aware of commercial realities and are slow to respond to business needs. They also expect more intensive involvement of HR support, believing that some tasks concerning pay and benefits, the appraisal process as well as health and safety issues require specialist expertise. In addition, coherent systematic support provided by HR specialists and the training of line managers is crucial as some of the latter may lack the appropriate skills for supervising their staff and implementing HRM practices in an effective way. However, Maxwell and Watson (2006) assert that the challenge for line managers and HR specialists does not just rest upon their relationship quality, for it also depends upon the ability and willingness of the former to carry out HR tasks properly (Renwick and MacNeil; 2002:407). Consequently, improvement of the relationship between line managers and HR specialists will motivate the former to use their knowledge and skills for effective HR.

\section{Proposition 5. Social interactions improving top management/HR/line manager relationships are positively associated with improvements in line managers' AMO.}

Appelbaum et al. (2000) adopt an employee-based perspective in their AMO model, which links people's ability-motivation-opportunity for implementing HRM practices with firm performance. 
Further studies have investigated the degree to which ability, motivation and opportunity of line managers predict the effectiveness of their implementation of HRM practices (BosNehles, et al., 2013; Whittaker and Marchington, 2003). Specifically, they aimed to measure the influence of line managers' performance level in terms of their ability, motivation and opportunity in implementing HRM practices, finding that having the skills and knowledge predicted their performance in this regard. In addition, if line managers are provided with clear-cut information with respect to their roles and responsibilities, they will be more effective in implementing HRM practices. Whilst Bos-Nehles et al. (2013) have found no effect of motivation on line managers' performance, Whittaker and Marchington (2003) have elicited that line managers' demotivation to execute HR practices is likely to decrease their level of performance in HRM systems implementation, which supports the following proposition.

\section{Proposition 6. Improvements in line managers' AMO is positively associated with their HRM implementation effectiveness.}

The proposed model considers ability-motivation-opportunity factors as a set of variables that mediate between the social context variables and line managers' HR implementation effectiveness. It is expected that social interaction factors, such as organizational culture, organizational climate, political considerations, top management HR support and/or social interactions are supportive of line managers' AMO. In turn, AMO level is anticipated to be positively associated with the effective implementation of HRM practices.

Proposition 7. Improvements in line managers' AMO strengthens the relationship between organizational culture, organizational climate, political considerations, top management HR support and line managers' HRM implementation effectiveness.

\section{DIRECTIONS FOR FUTURE RESEARCH}

In the related literature, the relationships among HR specialists, line managers and top management have been explored by various scholars. Some of them have emphasized how top management teams perceive HR professionals and the other staff in the department, whereas others have focused on how the employees and line managers view HRM and its effectiveness. This study has been geared towards an aspect that has not been comprehensively explored by the scholars and that is the vital role of the line managers in the effectiveness of the HRM implementation. The propositions developed through the model offer a new area of study in HRM for researchers that if pursued could lead to beneficial findings both for practitioners and academics. For future research, it is recommended that the above propositions are tested even with the addition of new variables to the model, such as line managers' leadership style (Vermeeren, 2014) and/or employees' perceptions of HR. 


\section{CONCLUSION}

Going beyond previously proposed frameworks, in this study a model of HR implementation effectiveness that incorporates social context theory and AMO theory has been provided. Specifically, several social-contextual factors, including organizational culture, organizational climate, political considerations, top management HR support and social interactions that can influence line managers' ability-motivation-opportunity factors for executing HRM practices have been covered. That is, line managers' AMO factors have been proposed as influencing the effectiveness of line managers' HRM systems implementation. It follows from this that line managers' ability-motivation-opportunity factors can be considered as the mediating dimension between social context factors and their HRM implementation effectiveness. Through this paper, we provide contributions to theory not only by attributing social context factors to the role of line managers in HRM delivery, but also by extending support for AMO as having an impact on their performance. As such, this work goes beyond an employee-based perspective that links employees' AMO with improved firm performance. Another contribution of the paper is that whilst the extant studies have placed emphasis on the close partner relationship between line managers and HR executives for producing effective HR outcomes, we have emphasized the need to extend this to a triad-relationship involving the top management team. For, as principal decision makers, top management and HR executives should be in continuous interaction with respect to the strategic HRM perspective as this would help line managers to embrace the role requirements related to HRM practices.

We have also pointed out how the characteristics of organizational climate dimensions, distinctiveness, consistency and consensus are linked with HRM practices. That is, the stronger the organizational climate, the less the likelihood of ambiguity and the more convergent understandings about HRM policies and practices amongst all members of the organization, the greater the probability of line managers, HR executives and employees willingly working towards effectiveness in HRM systems implementation. Accordingly, the proposed model could lead to valuable insights being uncovered by researchers as it would help them to examine the link between the strength of organizational climates and the strength of the HRM practices. Another inference that can be drawn from the model is that it is not purely the organizational factors, but also managerial contributions via abilities-skills and also opportunities provided to line managers that can bring about effective HRM systems implementation. Furthermore, the social context perspective will help in the understanding of organizational environments as this takes the aspects of political and interactional processes into consideration. Though, accountability as one of the dimensions of political consideration has not been extensively investigated, this study addresses the importance of political behaviors of line managers with respect to HRM implementation effectiveness.

In general, this study with its proposed model has been aimed at identifying the process through which social contextual factors may bring insights regarding line managers' effectiveness in HRM practices implementation. The model also indicates the importance of these managers' AMO aspects as crucial intermediaries between these factors and the effectiveness of line managers' HRM practices implementation. 
Further research efforts are necessary for testing this proposed framework so that a more complete model for ensuring HRM implementation effectiveness can be developed. From a practical viewpoint, such endeavors would provide top management teams and HR executives with a roadmap on how to develop line managers so as to ensure their effectiveness regarding HR outcomes.

\section{REFERENCES}

- $\quad$ Alfes, K., Truss, C., Soane, C. E., Gatenby, M. (2013). The Relationship Between Line Manager Behavior, Perceived HRM Practices, and Individual Performance: Examining the Mediating Role of Engagement, Human Resource Management, 52(6), 839-859.

- $\quad$ Appelbaum, E., Bailey, Tt, Berg, P., Kallenberg, A. (2000). Manufacturing advantage: Why high-performance work systems pay off. Ithaca, NY: Cornell University Press.

- $\quad$ Becker, B. \& Huselid, M. A. (2006). Strategic human resource management: Where do we go from here?, Journal of Management, 32, 898-925.

- Blumberg, M. and Pringle, C. (1982). 'The missing opportunity in organizational research: some implications for a theory of work performance'. Academy of Management Review, 7: 4, 560-569.

- Boxall, P. and Purcell, J. (2011). Strategy and Human Resource Management, 3rd edn, Basingstoke: Palgrave Macmillan.

- $\quad$ Bos-Nehles, A. C., Van Riemsdijk, M. \& Looise, J. K. (2013). Employee Perceptions of Line Management Performance: Applying the AMO Theory to Explain the Effectiveness of Line Managers' HRM Implementation, Human Resource Management, Vol. 52, No. 6, pp. 861-877.

- $\quad$ Camelo Ordaz, C. De La Luz Ferna'ndez-Alles, M., Valle-Cabrera, R. (2008). Top Management Teams Vision and Human Resource Management Practices in Innovative Spanish Companies, International Journal of Human Resource Management, 19(4), 620-638.

- Chow, I. H. (2012). The roles of implementation and organizational culture in the HR-performance link, The International Journal of Human Resource Management, 23(15), 3114-3132.

- Ferris, G. R., Arthur, M. M., Berkson, H. M. Kaplan, D. M., Harrell-Cook G., and Frink, D. D. (1998). Toward a Social Context Theory of the Human Resource Management-Organizational Effectiveness Relationship, Human Resource Management Review, 8(3), 235-264. 
- $\quad$ Gratton, L. \& Truss, C. (2003). The three dimensional people strategy: Putting human resource policies into action, Academy of Management Executive, 17(3), 74-86.

- Greenberg, J. (1988). Cultivating an image of justice: Looking fair on the job. Academy of Management Executive, 2, 155-158.

- Guest, D. (2011). Human Resource Management and performance: Still searching for some answers. Human Resource Management Journal. 21, 3-13.

- Huselid, M. A., Jackson, S. E., Schuler, r. s. (1997). Technical and strategic human resource management effectiveness as determinants of firm performance. Academy of Management Journal, 40, 171-188.

- $\quad$ Khilji, S. E. \& Wang, X. (2006). 'Intended' and 'implemented' HRM: The mssing linchpin in strategic human resource management research. International Journal of Human Resource Management, 17, 1171-1189.

- $\quad$ Li, X., Frankel, S. J., Sanders, K. (2011). Strategic HRM as process: how HR system and organizational climate strength influence Chinese employee attitudes, The International Journal of Human Resource Management, Vol.22, No.9, 1825-1842.

- Maxwell, G. A., Watson, S.(2006). Perspectives on line managers in human resource management: Hilton International's UK Hotels, International Journal of Human Resource Management, 17(6), 1152-1170.

- Nyameh, J. (2013). Moderating Effects of Organizational Culture on Human Resource Management and Employee's Performance, African Journal of Business Management, 7(28), 2767-2774.

- Omotayo Adowele, O. \& Adenike Anthonia, A. (2013). Impact of Organizational Culture on Human Resource Practices: A Study of Selected Nigerian Private Universities, Journal of Competitiveness, 5 (4), 115-133.

- Renwick, D. (2003). Line Manager involvement in HRM: an inside view, Employee Relations, 25 (3), 262-280.

- Renwick, D. (2000), HR-Line work relations: A review, pilot case and research agenda. Employee Relations, 22(2), 179-205.

- Renwick, D., MacNeil, C. M. (2002) Line Manager Involvement in Careers, Career Development International, 7(7), 407-414.

- Rousseau, D. M. (1990). Assessing Organizational Culture: The Case for Multiple Methods. In B. Schneider (Ed.), Organizational climate and culture. San Francisco, CA: Jossey-Bass. 
- Schein, E. H. (1984). A new awareness of organizational culture, Leadership and Organizational Studies, 103, 2802-85.

- Sikora, D. M. \& Ferris, G. R. (2014). Strategic human resource practice implementation: The critical role of line management, Human Resource Management Review, Vol. 24, pp. 271-281.

- Sterlin, A. and Boxall, P. (2013). Lean production, employee learning and workplace outcomes: a case analysis through the ability-motivation-opportunity framework, Human Resource Management Journal, Vol 23, no 3, 2013, pp. 227240

- Vermeeren, B. (2014). Variability in HRM implementation among line managers and its effect on performance: a 2-1-2 mediational multilevel approach, The International Journal of Human Resource Management, 25(22), 3039-3059.

- Wright, P. M. \& Nishii, L. (2006). Strategic HRM and organizational behavior: Integrating multiple levels of analysis. Cornell University ILR School, Center for Advanced Human Resource Studies (CAHRS), http://digitalcommons.ilr.cornell.edu/cgi/viewcontent.cgi?article=1404\&context =cahrswp.

- Wright, P. M., McMahan, G. C., Snell, S. A., Gerhart, G. (2001). Comparing line and HR executives' perceptions of HR effectiveness: Services, roles and contributions, Human Resource Management, 40(2), 111-123.

- Vroom, V. (1964). Work and Motivation, New York: Wiley.

- $\quad$ Siemsen, E., Roth A.V. \& Balasubramanian, S. (2008). How motivation, opportunity and ability drive knowledge sharing: The constraining factor model. Journal of Operations Management, 26, 426-445.

- Whittaker, S, Marchington, M. (2003). Devolving HR responsibility to the line: Threat, opportunity or partnership?, Employee Relations, 25 (3), 245-261. 